\title{
CRíticA DE LA CULTURA Y DEL ALMA TRÁGICA EN LA ENSAYÍSTICA TEMPRANA DE GYÖRGY LUKÁCS
}

Francisco Garcia CHICOTE*

\section{RESUMEN}

El trabajo aborda un factor central en la conformación del campo intelectual alemán durante el período guillermino: el concepto de cultura, cuya formulación más compleja se halla en la obra de Georg Simmel. Se afirma que las tempranas conceptualizaciones de György Lukács acerca de la tragedia constituyen una crítica destructiva del concepto de cultura y marcan un antecedente significativo en el desarrollo del marxismo occidental.

Palabras Clave: Valor, Rédito, Simmel, Marx.

\section{INTRODUCCIÓN}

Las siguientes páginas tratan, en general, sobre una corriente significativa del desarrollo del pensamiento burgués en Europa Central: aquella cuya naciente se ubica en las últimas décadas del siglo XIX y se encauza en las primeras del XX hasta nutrir los zanjones de los diferentes irracionalismos. Su manifestación más coherente lleva el nombre de filosofía de la vida y se halla asociada, en el plano político, al surgimiento, desarrollo y disolución del Imperio Alemán. En particular, se trata aquí de la afinidad entre, por un lado, una categoría central de esta corriente ideológica, la noción de cultura, y, por el otro, el ethos trágico.

La situación actual de la investigación sobre esta noción presenta el siguiente complejo de problemas. En primer lugar, la ensayística de Georg Simmel constituye la fuente más rica para dilucidar las relaciones entre cultura y tragedia: Simmel revierte la modificación de la que fue

\footnotetext{
* Doutor em Literatura pela Universidade de Buenos Aires (UBA), Buenos Aires, Argentina. E-mail: fgchicote@gmail.com.
} 
objeto el concepto durante su apropiación por parte de la Ilustración alemana. Categorías tales como formación, cultura e ilustración, que fueron despojadas del elemento crítico que habían ganado en Francia (por ejemplo, en las reflexiones de Jean Jacques Rousseau) para constituirse en herramientas de la perfectibilidad humana, vuelven a adquirir en la obra de Simmel una carga negativa que impugna el progresismo ilustrado. Así, por ejemplo, se insiste a lo largo de la obra de Simmel en el carácter "crítico", "conflictivo" e incluso "trágico" de la cultura para afirmar que los mismos procesos que procuran la dignidad del ser humano conducen a su alienación. En segundo término, el interés por la obra de Simmel ha crecido significativamente en los últimos treinta años - un período que coincide con la publicación de sus obras completas-, al punto que se dijera en 1998 en New German Critique que "como el mercado bursátil mismo, el capital cultural de Simmel ha estado en ascenso en las últimas dos décadas" (LECK, 1998, p. 109). Sin embargo, impera una comprensión abstracta del problema de la cultura; es decir, no en los parámetros axiológicos de su concreto surgimiento y desarrollo en el campo intelectual alemán (ELIAS, 2009; BAECKER, 2002; MARCUSE, 1970), sino en términos neutrales. Así, la "tragicidad" de la cultura es concebida como un reminder de los excesos de la razón y llama resignada pero dignamente a la comprensión de que las alienaciones son condición humana, y que la crítica consiste en su constante denuncia. Esta interpretación liberal del Simmel se encuentra en la base de la instauración del filósofo de Frankfurt como "sociólogo de la modernidad" y se repite en críticos de diversa índole (cf. FRISBY, 1985, p. 60; GIL VILLEGAS, 1997; GARCÍA, 2008, p. 59). En tercera y última instancia, al desustanciar el concepto de cultura trágica en Simmel, se diluye parte de su constelación conceptual: destino, conflicto y carácter no remiten a categorías concretas que presuponen una ética y una cosmovisión igualmente concretas, sino nociones leves llamadas a reforzar el supuesto carácter crítico de la teoría cultural de Simmel.

Si la ensayística de Simmel proporciona la manifestación más coherente del problema de la cultura, en la obra de temprana de György Lukács se halla la concreción más clara del problema de la tragedia. Por una parte, el concepto de género literario en el joven Lukács diverge sustancialmente de la concepción exclusivamente epistemológica que, 
con aisladas excepciones, prevalece actualmente en las academias de los países centrales. Se trata para Lukács de formas compositivas determinadas, de modos de producción que ya en 1906 el joven ensayista vinculaba con la especialización de los sentidos. Mediante intensificación y negación, la forma literaria expresa de manera agudizada un problema que resulta crucial para el ser humano, pero que es imposible de divisar en las relaciones cotidianas. De ahí que el problema del género literario esté ligado, para el joven Lukács en 1913, no solo a formas peculiares del conocimiento del ser humano - "[c] ada forma de la poesía interroga sobre la esencia del ser humano"-, sino también a cuestiones éticas, pues el modo en que se intensifica el problema varía "en tipo y en grado" según las formas respectivas de cada género (LUKÁCS, 1974, p. 53). Por otra parte, Lukács concibe la forma trágica en estrecha relación con la esencia general del drama, y a esta con el pensamiento filosófico. En su Historia evolutiva del drama moderno, el joven húngaro coloca al drama "en el lugar más próximo a la filosofía" (GLW, 15, p. 33), pues al constituir la esencia de este en la expresión más crasa de la "paradojal relación fallida entre el efecto intencionado y los medios que se encuentran a disposición para ello" (GLW, 15, p. 26, el destacado es nuestro), se "elevan a conciencia en gran medida los problemas más profundos de la vida" (GLW, 15, p. 33). De ahí que se conciba a la tragedia como la forma más intrínseca del drama: en ella el conflicto entre una voluntad humana y todo lo que se interponga en su camino no solo deviene en significación de toda la vida del personaje, sino que también la interferencia de los medios objetivos se carga densamente como destino (GLW, 15, p. 36).

El interrogante por los vínculos entre conceptos de diferentes esferas del conocimiento debe fundamentarse metodológicamente, tanto más cuanto se premia hoy en día lo que Marx llamó, al criticar los efectos deformantes de la especialización capitalista, "el idiotismo de oficio" (1987, p. 112). De compartir algo, tragedia y cultura lo hacen sobre el terreno de una misma "concepción del mundo". Lucien Goldmann (1986) desarrolla esta categoría como instrumento conceptual de trabajo que le permite comparar no solo obras ideológicas individuales aparentemente diversas, sino incluso pertenecientes a diversos ámbitos (para el caso, literatura y filosofía). Si bien Goldmann toma este término de la filosofía de la vida (de Wilhelm Dilthey), lo modifica en términos de 
una "conciencia colectiva" de un grupo social e históricamente definido. Esta conciencia colectiva se convierte en concepción del mundo cuando reúne las aspiraciones, los sentimientos y las ideas del ser humano en general; es decir, cuando se trata de una conciencia de una clase social (1986, p. 28). Goldmann no lo explicita, pero su exposición concibe este instrumento en el sentido de lo que Marx llamó, en el boceto de la resolución metodológica de la economía política y de la ciencia en general, una "categoría simple", sujeta a un constante "camino de ida y vuelta" que puede ser descripto esquemáticamente del siguiente modo: se la abstrae a partir de la inmediatez empírica para que luego vuelva sobre esta. Así, se revela ahora como una "rica totalidad con múltiples determinaciones y relaciones" lo que antes resultaba "una representación caótica del conjunto", y el proceso vuelve necesariamente a tener lugar (MARX 1980, p. 301). En palabras de Charles W. Mills, tal categoría devela "puntos estratégicos de intervención": indica qué es central, qué secundario, y cuáles son las claves para la dilucidación de las relaciones de las partes entre sí y con el todo (1969, p. 15). En el análisis de una concepción del mundo, destacan los "individuos excepcionales": aquellos que logran representar, conceptual o imaginativamente, con la mayor coherencia-objetivamente- posible esta conciencia colectiva.

Las siguientes líneas defienden la hipótesis de que las aproximaciones teóricas del joven Lukács al problema de la tragedia como género develan el aspecto celebratorio de la muerte que posee la "crítica cultural" propia de la filosofía de la vida y en especial de Georg Simmel. Esta crítica de la teoría de la cultura -teoría en la que Simmel aparece como exponente excepcional- cimenta, aún en sus signaturas equívocas, el punto de partida de un modo de pensamiento que dará luz a lo que ha dado en llamarse "marxismo occidental". Se constatará de hecho que los impulsos del joven Lukács en torno al problema de lo trágico allanan el camino para lo que luego fue develado, en las obras del propio Lukács, como el verdadero fundamento objetivo de lo trágico: una vida del interior basada en aquella categoría que Marx definió como rédito.

Se divide la argumentación en tres tramos. En primer lugar, se destacarán los elementos definitorios de lo que Lukács concibe como "alma trágica" en el ensayo "Metafísica de la tragedia", con el que se cierra El alma y las formas. En segundo lugar, se comparará la noción 
así abstraída de alma trágica con el concepto de cultura de Simmel. En tercer y último término, se analizarán las críticas del joven Lukács al alma trágica y el modo en que esta es superada en Historia y conciencia de clase.

\section{Alma trÁGicA}

En el ensayo "Metafísica de la tragedia", de 1911, Lukács presenta Brunhild, pieza teatral de Paul Ernst, como caso paradigmático de la forma trágica y destila de ella el alma trágica en tanto único modo realmente humano de existencia. El ensayo que le precede en El alma y las formas desarrolla un fallido diálogo de sordos, un absurdo duelo retórico entre dos amigos presenciado por una joven estudiante. Se trata allí de la imposibilidad del convencimiento, de la bajeza e insustancialidad de las formas sensuales del eros, del carácter irrebasablemente contingente del vínculo entre medios y fines, del vacuo interés de los hombres mediocres por el placer sensorial, por el relativismo y la diversidad, y de la degradación infame de la verdad. La conversación, que acaba tan azarosamente como comienza y nada resuelve, gira en torno a la narrativa de Sterne, considerada por el más "hombre" de los dos amigos como una forma "amateur" continuadora de Cervantes, obsesionada por la multiplicidad objetual de la empiria. "Inorgánico", el principio compositivo de Sterne solo ofrecería "fragmentos" de la realidad, "no porque no pu[ed]a consumar" sus obras, "sino porque en ninguna parte vio nunca valor y disvalor, y porque no eligió nunca entre ellos. No compuso sus obras porque careció de la condición más elemental de toda concepción, del poder de elegir y valorar" (LUKÁCS, 1985, p. 227, el destacado es nuestro).

A diferencia del ensayo sobre Sterne, "Metafísica de la tragedia" no se cierra con un beso entre una mujer y un amante de la confusión de la vida; tampoco asume la forma de un diálogo. El diagnóstico de la vida cotidiana -o, para usar un término propio de esta etapa del desarrollo del filósofo, de la "realidad vivencial"- es ciertamente el mismo: Lukács define allí la vida burguesa como un ámbito de imposible realización del alma, es decir, un ámbito en el que los valores y la facticidad se confunden entre sí, un terreno en el que resulta por ende imposible 
regirse con arreglo a los fines del alma. En la vida, todo es confuso, impuro, incierto; nada allí se consuma completamente. Esta falsa vida se ampara en el flujo ininterrumpido de ambiguos eventos, siempre en transición, y el alma, lo único divino y esencial del ser, se llama a silencio ante el imperio de una racionalidad vacía que entiende los despliegues de la existencia en términos de causa y consecuencia. Se trata de una existencia de segundo orden que impone la cuantificación de la calidad: en la edad de la equiparación de derechos, todo es igualado y rebajado a tonalidades de grises.

En efecto, la forma correlativa política a esta existencia es la democracia, o su expresión más consecuente, el socialismo. "Los demócratas", afirma Lukács, "que han pensado claramente hasta el final su reivindicación de derecho igual para todos los hombres han negado siempre el derecho de la tragedia a la existencia" (LUKÁCS, 1985, p. 272). Pues el joven húngaro encuentra en la tragedia la figuración paradójica de una existencia plena. En la simulación comprimida, desprovista de toda ambigüedad, condensada hasta el límite de lo posible, de la tragedia clásica le sería dado a una casta superior de hombres la plasmación de su esencia en una forma inequívoca, en una figura llena de sentido. Esta dación de forma es el encuentro del alma solitaria con su destino individual, y ella significa la suspensión in extremis de todas las determinaciones alienantes de la vida. En efecto, el mundo de la tragedia constituye para Lukács la aniquilación de todas las formas de la procesualidad: la temporalidad, la duración, son todas ellas categorías contaminantes propias de la existencia cotidiana, regida por la confusión entre valor y facticidad: allí, los valores se subsumen en relaciones objetivas que nada tienen que ver con la naturaleza anímica de estos. En la medida en que la tragedia ha de representar en términos de necesidad el encuentro en un instante milagroso del alma con su destino escrito desde siempre, no puede haber en ella tiempo. Que haya peripecia, que transcurran horas y se presenten diálogos en la obra solo es índice para Lukács de la paradoja que implica representar una experiencia mística "con palabras humanas". Bien entendidas, las acciones son meramente decorativas, como meramente decorativas son asimismo los diálogos, pues no hay desarrollo formativo en el ser del héroe, "que est[á] muert[o] mucho antes de morir" (LUKÁCS, 1985, p. 253). 
Bajo la apariencia de acción se esconde el sentido profundo de necesidad del que se nutre el ethos trágico. Es apariencia porque las decisiones entre alternativas del héroe ni provienen de alternativas reales (esto es, no existen independientemente de él), ni forman su carácter: este ya está hecho y las acciones simplemente lo confirman. En ocasión de otras reseña de Paul Ernst, Lukács dirá en 1913 de la tragedia en tanto "drama paradigmático" que su héroe es un hombre "que se consuma y lo hace a partir de sí, que no permite que nada que remita más allá de él entre en su vida, y utiliza el destino (que rompe la envoltura de la empiria) como cincel para consumar de manera autocrática el propio, eterna y apriorísticamente inmanente exclusivamente a partir de su propio impulso" (1974, p. 54). De ahí que, a diferencia de los hombres mediocres de la empiria, que aman la vida y celebran sin sortearlos los obstáculos que ella les opone, los dignos de la existencia trágica -de la muerte trágica- aceptan consciente y responsablemente todo su destino. El hombre trágico, sostiene Lukács, aglutina valientemente en su figura los eventos exteriores de su vida admitiéndolos como pertenecientes a su esencia interna a través de una actitud de "culpa". Independientemente del grado de responsabilidad real que detente, el hombre superior acepta sin chistar todo lo que el mundo le arroja, como si fuese expresión de su interior.

El hombre sabe de su destino y llama a ese saber culpa. Y puesto que siente como acción suya lo que tuvo que sucederle, abraza con tajante contorno en sí todo lo que cae casualmente con el fluido ámbito de su casual complejo vital. Lo hace necesariamente; crea límites en torno suyo; se crea a sí mismo. Pues visto desde fuera no hay culpa alguna, ni puede haberla; cada cual ve la culpa del otro como complicación y azar, como algo que con el más pequeño cambio de un hálito de viento habría podido ser de otra manera. Pero mediante la culpa el hombre dice Sí a todo lo que le ha ocurrido, y como lo siente como su acción y como su culpa, lo conquista y forma su vida poniendo su tragedia, nacida de su culpa, como límite entre su vida y el todo. Y los grandes hombres delimitan más que los bajos y no pierden nada que en alguna ocasión haya pertenecido a su vida: por eso la tragedia es su privilegio (LUKÁCS, 1985, p. 261s.) 
Así se prepara el alma de la tragedia para la plasmación de una figura inequívoca del ser interior, atemporal del hombre en un instante milagroso, cuya emergencia es accidental, incalculable, insondable en parámetros de la racionalidad y completamente refractaria a las explicaciones de razones y efectos.

Filosofía DE LA VIDA, CULTURA Y DESTINO

La perspicacia de Lukács consiste en haber visto en la obra trágica de Paul Ernst la traducción literaria de la teoría de la cultura de Simmel, por más que este impugnara abiertamente las corrientes estéticas clasicistas. A fines de comprender este vínculo, ha de advertirse que el concepto de cultura, lejos de detentar una significación neutral, tiene para los intelectuales alemanes de este período un significado axiológico. "Cultura" remite aquí a la perfectibilidad humana, al devenir ser humano del ser humano, a la superación de las alienaciones.

Norbert Elias encuentra el origen de este concepto hacia mediados del siglo XVIII, cuando comienza a constituirse como factor de la autoconciencia de una incipiente burguesía alemana, en un intento de legitimación ideológica frente a una nobleza que, luego de la Paz de Westfalia, había asumido formas "francesas" (ELIAS, 2009, p. 90ss.). Así, se conjugan en el seno de este concepto factores ideológicos para el apuntalamiento histórico-universal de la burguesía con elementos nacionalistas. Herbert Marcuse (1970) analiza cómo, durante el proceso de consolidación masiva -a partir de la segunda mitad del siglo XIX-, de la perspectiva ideológica de la burguesía reaccionaria, el concepto de cultura canalizó, de una manera idealista, antimaterialista y ahistórica, todo aquello que la burguesía ascendente había prometido para el plano de la realidad efectiva (p. 52.). La cultura remitiría a expresiones ideológicas -artísticas, filosóficas, religiosas- de una esencia definida contrapuesta a la "civilización". Frente al carácter procesual, dinámico, potencialmente generalizador de la civilización, que comprende los factores técnico-tecnológicos, científicos y económicos propios del avance del capital, la cultura se ofrece como la exteriorización de una profundidad auténtica en virtud de su irracionalidad y denuncia los objetos de la civilización en tanto pertenecientes a una realidad 
de segundo rango, constituida de facticidad y susceptible de ser abordada por las categorías del entendimiento. De este modo, "cultura" adquiere una doble y paradójica signatura. La cultura $-\mathrm{y}$ con ella la "crítica cultural"- aparece inmediatamente crítica, pues se contrapone en cuanto valor a la facticidad de la realidad alienada y alienante del mundo material. Mediatamente "afirma" empero al mundo alienado en la medida en que el suyo es, desde el punto de vista de su constitución más íntima, irrebasablemente diverso del de la civilización, y deja a este intacto (cf. MARCUSE, 1970, p. 50s.). Este carácter cómplice de la teoría de la cultura llamó la atención de Bertolt Brecht y Theodor Adorno (cf. BRECHT, 1995, 18, p. 446ss.) y llevó a este último a examinar su función ideológica en el desarrollo de los genocidios cometidos por el Estado alemán. Se lee en Dialéctica negativa que si la cultura "aborrece el hedor es porque ella misma hiede; porque, como dice Brecht en un magnífico pasaje, su palacio está hecho de mierda de perro [...] En esos santuarios del espíritu, en la pretensión enfática de su autarquía es precisamente donde radica la mentira" (ADORNO, 2002, p. 333).

La imbricación de esta noción de cultura en constelaciones conceptuales particulares constituye un aspecto fundamental de la corriente ideológica dominante en Alemania durante el período guillermino y la República de Weimar, la filosofía de la vida. Tal imbricación alcanza un grado de complejidad impar en la obra de Simmel, para quien "cultura" mantiene el carácter axiológico, pero se le introduce un elemento irrebasablemente negativo. En el discurso de 1916 "La crisis de la cultura", por ejemplo, la define como

aquella consumación del alma que no se alcanza por sí sola como sucede en su profundidad religiosa, en su pureza moral o en la creatividad primaria, sino en la medida en que toma el desvío por las creaciones del trabajo genérico espiritual-histórico: a través de la ciencia de las formas vitales, arte y estado, profesión y conocimiento del mundo va el camino cultural del espíritu subjetivo, sobre el que este regresa a sí mismo, ahora en un nivel más alto y más consumado (GSG, 13, p. 190). 
Para Simmel, la facultad expresiva del alma -considerada como la finalidad por antonomasia pues aspira a la conformación de un carácter internamente armonioso llamado "personalidad" (cf. SIMMEL, 2005a, pp. 98s. y 210)- asume un carácter crecientemente complejo en el que su productividad y su existencia dependen cada vez más de medios, cuya naturaleza no es anímica, sino que responde a las leyes de la facticidad. Al ocupar posiciones predominantes en la existencia de los individuos, los medios adquieren la falsa apariencia de fines, se anquilosan y dejaban de servir a la expresividad anímica.

La estructura básica de esta oposición es la que existe entre valor y facticidad objetiva, que se halla ya en la definición que hace Heinrich Rickert del ámbito cultural y que determina el concepto simmeliano de actividad desde La filosofía del dinero. En la medida en que se concibe como actividad cuyo fin es la consumación del alma, la cultura reúne expresiones y expresividades de la dignidad del ser humano. Sin embargo, en la medida en que se trata de una actividad, esta debe per definitionem afrontar la contaminación de las estructuras objetivas que nada tienen que ver con el valor anímico. Al subsumir su teoría de la actividad en el punto de vista del individuo, Simmel la entiende como un intercambio entre dos agentes (2013, p. 69ss.). Consecuentemente, el valor último de un objeto no solo es arbitrario -porque depende de su capacidad para satisfacer una necesidad que no se origina en el agente productor, sino en el receptor-, sino que también la producción de objetos -que se traducen en valores para el receptores necesariamente alienante para el productor (esto es, constituye en palabras de Simmel "un sacrificio" -2013, p. 71-), puesto que el valor es independiente de la cantidad y la calidad del trabajo. Como indica Youssef Ishagpour (1975, p. 14), aquí radica el núcleo del concepto simmeliano de cosificación: la contraposición entre valor (en definitiva, una apreciación subjetiva) y objeto. Conceptualizaciones posteriores -ante todo, la de Lukács-, divergen radicalmente de la simmeliana porque consideran el trabajo abstracto como un aspecto constitutivo del valor, y así superan el callejón sin salida de dualismo sujeto-objeto.

Como los procesos objetivos no dan cuenta del valor -culturalde un objeto (antes bien, lo deterioran), el valor -cultural- no puede ser aprehendido mediante las categorías del mundo objetivo, tales como causa y efecto. En "El concepto y la tragedia de la cultura", de 1911, 
afirma de hecho cuán engañoso puede resultar entender el valor cultural en los parámetros de causa y efecto: "así como las objetivaciones del espíritu son valiosas más allá de los procesos vitales subjetivos que han pasado a formar parte de estas como sus causas, así también lo son más allá de los otros procesos que dependen de ellas como sus consecuencias" (2005a: 103). De manera coherente, Simmel afirma en 1913 que la relación entre acción y personalidad, la trabazón armoniosa del interior humano, es "contingente":

La contingencia de la relación que existe entre nuestros actos, como meros hechos anímicos y como valores dentro de las series reales, tiene, por consiguiente, su continuación entre los primeros y la significación de su contenido para la formación de nosotros mismos como personalidad objetiva, como hechura vital cerrada (2005b, p. 25).

El mundo objetual adquiere necesariamente una signatura alienante: los valores allí expresados no son asumibles por el sujeto para el desarrollo de su autoconciencia, sino que amén de su objetualidad se autonomizan -se fetichizan- (GSG, 13, p. 192) y el alma se empobrece -se cosifica-.

Desde el punto de vista individual, la comprensión de este conflicto de la cultura, cuya resolución no se halla en el ámbito de la praxis humana -precisamente porque esta no puede superar la oposición entre objeto y valor- es condición para lo que la filosofía de la vida concibe como la dignidad última de la existencia humana: la constitución de una personalidad. De esto se trata el ensayo de Simmel sobre el destino, de 1913. Desde un punto de vista meramente fáctico, destino es toda serie objetiva real que de manera accidental impide o estimula la realización de una finalidad; ahora bien, cuando el problema del destino se traslada al ámbito de la cultura, esto es, la actividad por la que el alma intenta consumarse, destino es la comprensión de la tragicidad irrebasable que subyace a la expresión del alma, comprensión que fortalece la formación de una personalidad. En el ámbito de la cultura, el destino no es simplemente algo otro sin finalidad que sale casualmente a nuestro encuentro, sino el encuentro del alma con sus expresiones que forzosamente adquirieron una existencia objetiva. Esta relación es la plasmada por la tragedia, de acuerdo con Simmel: "Solo 
la forma de arte que representa la tragedia", afirma en 1913, "nos deja entender que lo que es coincidente es de hecho una necesidad hasta lo más profundo", pues "lo verdaderamente humano, nuestra auténtica determinación es colocarnos en el destino" (GSG, 12, p. 489s.).

\section{FILOSOFÍA DEL RÉDITO}

La significación del ensayo "Metafísica de la tragedia" en el desarrollo intelectual de Lukács no puede determinarse unívoca e inequívocamente. La "rigidez estatuaria" con que Lukács define el carácter del héroe, la necesariamente intransigente "ética absoluta" que le asigna a su conducta, el irremontable abismo que declara entre, por un lado, los valores como tesoro de la interioridad y, por el otro, los objetos en cuanto obstáculos de la "así llamada vida", y la consecuente celebración del sacrificio como único índice de autenticidad de la dignidad constituyen las piedras basales de lo que, a partir de fines de 1918, el comunista Lukács propondrá como verdadero proceder político. Esta continuidad entre la caracterización de la tragedia del apolítico Lukács y los fundamentos de su programa terrorista fue advertida ya en 1922 por Siegfried Kracauer: en carta a Margarete Susman del 11 de agosto, Kracauer pone en duda el eventual mérito que el "libro sobre la historia" en el que, según ha oído, estaría trabajando Lukács (esto es, Historia y conciencia de clase). Para Kracauer, que ya transitaba por entonces un proceso crítico que resultaría en la elaboración de una teoría social-revolucionaria inequívocamente marxista, la política del filósofo húngaro carecía de una noción de historia, pues consistía únicamente en la activación práctica de elementos idealmente formados cuya virtud radicaría precisamente en su carácter no procesual. A los ojos de Kracauer, el comunismo de Lukács consistiría en una trasposición política de los valores del interior tal como estos aparecen en El alma y las formas; una trasposición que, filosóficamente sustentada en una fichteanización de Kant, se realizaba por una ética de la "decisión à tout prix" reservada únicamente a "hombres de las más altas cualidades" (Kracauer a Susman 12/8/1922, DLA Marbach am Neckar).

A partir del fracaso, en 1921, del intento revolucionario alemán que llevó el nombre de "Campaña de marzo" y, en 1920, de las críticas 
del propio Lenin, Lukács superó el elemento trágico en su concepción política y pasó a considerarlo como uno de los polos de la alternativa falsa entre tipos de organizaciones terroristas (como la conformación del Partido Comunista húngaro durante la República de los Concejos) y de masas (cuyo ejemplo más destacado es el Partido Socialdemócrata alemán). De esta superación se trata Historia y conciencia de clase. Allí se critica al sectarismo y a la socialdemocracia en tanto desconocedores del carácter social de las instituciones, lo que conduce a que ambos se enfrenten a ellas como a una "segunda naturaleza" (1969, p. 93). A la muda e impenetrable coseidad de las formaciones objetivas estos tipos organizativos contraponen el universo axiológico del interior, cuya dignidad nunca se pone en duda. El partido de masas, que tal como había señalado Weber combina el carácter mecánico, proletarizado, desactivado de las masas con la misteriosa profundidad de la personalidad del líder (1979), supedita sus procedimientos a las formas institucionales burguesas, y por tanto no solo desconoce el vínculo que estas detentan con el modo de producción que el partido pretende abolir, sino que también asume frente a ellas el mismo comportamiento contemplativo, desactivado, en suma cosificado y cosificante que subyace al trabajo capitalista; es el economicismo la visión general de esta posición. A diferencia de la organización de masas, el programa político desplegado por la secta terrorista no reproduce las formas de la coseidad capitalista, sino que encuentra su raison d'être en la interioridad del terrorista, íntegramente dedicada a la destrucción total del mundo exterior; la ética constituye aquí el primum movens. Develando el vínculo estrecho que detentan el economicismo "objetivista" de Eduard Bernstein y el programa "subjetivo" y voluntarista de Otto Bauer, Lukács afirma en el ensayo "Rosa Luxemburgo como marxista" que el "fatalismo económico y la nueva fundación ética del socialismo van íntimamente juntos": en ambos casos, es dejada de lado la relación dialéctica entre objeto y sujeto, configuradora real de la totalidad social, y esta adquiere así la forma efectiva de "destino":

Para el individuo, ya se trate del capitalista, ya del individuo proletario, el mundo circundante, el ambiente social (y la naturaleza como reflejo y proyección de este) tiene que presentarse como un destino absurdo y brutal, como algo que eterna y esencialmente le 
es extraño. Él no puede entender ese mundo más que aceptándolo, en la teoría, de acuerdo con la forma de las "leyes eternas de la naturaleza", o sea, solo si ese mundo cobra una racionalidad ajena al hombre, impenetrable y no influible por las posibilidades de acción del individuo; solo si el hombre se comporta con ella de un modo puramente contemplativo, fatalista $(1969$, p. 41 s.).

Historia y conciencia de clase no solo denuncia el vínculo, la correlación entre lo que perfilaba, hacia el cambio de siglo, como dos formas estrictamente opuestas de la organización política -y encuentra el correlato filosófico de estas en la primera y en la segunda críticas kantianas (1969, p. 42)-, echando por tierra el análisis de Weber, cuya impugnación de la "ética de la convicción" conducía a una reivindicación -ciertamente tibia y resignada- de los partidos parlamentaristas. Asimismo, divisa en este núcleo común las expresiones políticas y científico-filosóficas del punto de vista de la burguesía, tal como se da en el complejo rédito-capital analizado por Marx en 1867. Para Marx, los fundamentos ideológicos de la burguesía asumen alternativamente las formas misteriosas, "humanas", de una vida apoyada en el rédito, y las formas despiadadas, únicamente susceptibles de ser aprehendidas por el cálculo, propias del capital. Por motivos que hacen a la realidad empírica del capitalismo desarrollado, el burgués no puede vincular el carácter expansivamente abstracto de su actividad capitalista con el ámbito en que él ha de realizarse como individuo y que se funda en el rédito. Por lo tanto, alternativamente ha de concebir o bien su fondo de consumo propio (esto es, el rédito) como algo sustraído al capital o bien a este como un sacrificio respecto de su libre desarrollo como individuo. Es decir, ha de considerar al ámbito interior posibilitado por el rédito de manera misteriosa como el único fundamento digno de su humanidad. En palabras de Marx:

Al desarrollarse el modo capitalista de producción, al crecer la acumulación y la riqueza, el capitalista deja de ser la mera encarnación del capital. Siente un "enternecimiento humano" por su propio Adán y se civiliza hasta el punto de ridiculizar como perjuicio del atesorador arcaico la pasión por el ascetismo. Mientras que el capitalista clásico estigmatizaba el consumo individual como pecado contra su función y como un "abstenerse" de la acumulación, el capitalis- 
ta modernizado está ya en condiciones de concebir la acumulación como "renunciamiento" a su afán de disfrute (1985, I, p. 733).

El punto más alto de conciencia que la perspectiva burguesa puede adquirir de este desgarro es, lógicamente, la de un destino trágico, al que Marx parodia recurriendo a Goethe, otro gran crítico de las actitudes trágicas: "Dos almas moran, ay, en su pecho, y una quiere divorciarse de la otra" (1985, I, p. 733). Para Lukács, esta disociación adialéctica entre el interior y el exterior señala el fundamento objetivo de la separación entre el mundo del valor, por un lado, y el mundo de la mera facticidad, por el otro. Se trata entonces en Historia y conciencia de clase de conceptualizar una forma organizativa que no se siguiera de una perspectiva burguesa, cuya plasticidad más aguda, más pura, se encuentra en la en forma trágica, sino que se desprenda de la categoría misma de trabajo. Remitiéndose a este punto central del conjunto de ensayos de 1923, afirma su autor tres años más tarde: "[T]odo [el] libro gira en torno a esta cuestión: el rol del Partido en la Revolución" (2015a, p. 18). Historia y conciencia de clase constituye por tanto un ensayo de superación del alma trágica, presente de manera determinante en la teoría y la praxis políticas de Lukács entre 1918 y 1921/2.

De ello no se sigue, sin embargo, que el alma trágica constituya el basamento de la ética de Lukács al momento de escritura de El alma y las formas, a pesar que ese libro marque, como sostiene Lucien Goldmann, "una etapa importante para el nacimiento de la filosofía existencialista moderna" (1969, p. 49). En efecto, György Markus (1977) y Miguel Vedda (2015) han advertido contra la idea de que los trabajos presentes en El alma y las formas pueden ofrecer una cabal silueta intelectual del filósofo por aquellos años. Por el contrario, parecería obrar en Lukács un impulso de buscar soluciones no siempre concordantes entre sí al problema general de la alienación, es decir vías para la realización -en el plano teórico- de una existencia cotidiana adecuada al ser humano. Estos "ensayos" de una vida digna se ordenarían para Markus en torno a "dos niveles de análisis": "se trata de la pregunta acerca de si el real estado de cosas por ese entonces era una expresión de la tragedia ontológico-existencial de la cultura o simplemente una expresión de una crisis histórica, y por ello resoluble” (1977, p. 99). La praxis teórica del joven Lukács habría consistido así en una constante experimentación 
sobre el vacío y de esto se seguiría, según Markus, que haya sido precisamente el ensayo la forma de expresión de este comportamiento "caleidoscópico". Vedda encuentra dos caminos preponderantes dentro del "incierto diagnóstico" del filósofo por esos años: por un lado, una perspectiva neoclásica, ahistórica, aristocrática y alejada de la vida cuyo exponente contemporáneo lo constituyen las tragedias de Paul Ernst; por el otro, una salida democrática, que atiende a las formas épicas, reniega de la muerte y anticipa factores no secundarios de la filosofía de su etapa madura (VEDDA, 2015, p. 20s.). En la potencia de cada una de estas dos perspectivas ensayadas al vacío residiría la extraordinariedad del joven Lukács.

Lukács vincula cultura y tragedia explícitamente en "Cultura estética", un ensayo concebido al mismo tiempo que "Metafísica de la tragedia". Allí, se interroga si la cultura es realmente una existencia no alienada $\mathrm{y}$, amén de un concepto de totalidad, de recíproca coordinación sujeto-objeto ofrece recursos para comprender el ethos trágico no solo como una consecuencia de la exigencia de la cultura, si también como una actitud tan alienada, tan "vital" como la mera vida misma y peligrosamente cercana al diletantismo moralista de la pequeña burguesía. La cultura es impugnada en este ensayo como un total desencuentro del sujeto respecto del objeto, como el absoluto no reconocimiento de la coordinación recíproca entre la actividad del sujeto y el carácter irrebasablemente condicionante de los objetos que existen fuera de la conciencia.

Para designar el comportamiento que se deriva de esta situación generalizada, el joven Lukács emplea sugerentemente un término caro a la filosofía de la vida, "Stimmung", que significa en alemán "estado de ánimo". Prestado de la reflexión en torno a la carga subjetiva de las artes plásticas, y en especial de la representación pictórica de la naturaleza, el término adquiere una carga conceptual determinada en la ensayística de Simmel, y refiere a la determinación vivencial, irracional, subjetiva, de la posición de unidad y totalidad. En su "Filosofía del paisaje", de 1913, se concibe el paisaje como propiedad exclusiva de la conciencia, que pone un todo unitario, por encima de los elementos, "no ligado a su significación aislada y no compuesto mecánicamente a partir de ellos". En la medida en que surgiría históricamente como resultado de la "individualización de las formas de existencia", cuando "la vida que 
palpita en la intuición y el sentimiento" se separa de unicidad originaria natural, el paisaje no deja de ser "una forma de la tragedia del espíritu", pero también un caso prototípico a partir del cual se pueden abstraer claramente las determinaciones básicas de la creación artística, y en ese sentido, el modo de obrar puro de una presunta "vivencia indivisa del pensar". El estado de ánimo designa, en esta línea argumentativa, "el portador más importante de la unidad" que ordena el flujo informe de la vida y simula una actividad sin contaminación por parte de los medios objetivos (1986, p. 178ss.).

La definición de Stimmung en "Cultura estética" se corresponde con la de Simmel, pero se la impugna en tanto falsa. Lukács la entiende como un comportamiento propio de la perspectiva de la cultura, centrado en el sujeto, no analítico, instantáneo, causal, que se extiende hacia "la totalidad de la vida y la vida entera se configura como sucesión incesante de estados de ánimo" (2015, p. 188). Frente a la consolidación de esta arbitrariedad subjetiva, "los objetos dejan de existir porque todo se vuelve mera posibilidad anímica", y se glorifica una soledad subjetiva total que se siente soberana de su interioridad y renuncia abnegadamente a la acción. Pero dado que la autonomía del estado de ánimo, su presunta pureza se sigue de su empobrecimiento, de la fallida concientización del carácter determinante de la realidad objetiva, la soberanía que pregona es el peor de los sometimientos. Porque no conoce que su interioridad es "causada", la ética que profesa la filosofía de la vida es, de acuerdo con este Lukács, "meramente un goce de la vida", "es la degradación espiritual elevada a principio de la vida". Para Lukács, pues, el estado de ánimo devela las contradicciones del alma trágica, que oscila entre un desborde arbitrario y una sumisión absoluta. Su incapacidad para intervenir significativamente en el decurso histórico la convierte en cómplice necesario: "[1]a tragedia permanente es la mayor frivolidad [, pues e]1 sentimiento de lo eternamente trágico le da la absolución a cualquier insiginificancia" (2015b, p. 193s.).

\section{CONCLUSIÓN}

En las páginas precedentes hemos mostrado el modo en que Lukács percibe ya en sus desarrollos de juventud la afinidad entre un 
concepto clave de la corriente ideológica dominante durante la época guillermina, la noción de cultura, y la celebración trágica de la muerte. La denuncia de esta afinidad persiste como elemento fundamental en la obra que inaugura el marxismo occidental, Historia y conciencia de clase, y presupone no solo una crítica del concepto de valor, sino también la comprensión de que se trata de una perspectiva típicamente burguesa. En lo que hace a la efectividad de la filosofía de la vida en la antesala de la Gran Guerra de 1914, la explicitación de sus vínculos con el alma trágica puede acaso echar luz sobre el "servilismo", ya constatado por Emil Lederer en 1915, con que "todas las corrientes se perdieron en el hecho de la guerra y creyeron encontrar vida en ella [;] no h[ubo] ninguna corriente intelectual y ninguna corriente cultural en Alemania y fuera de ella que no estuviese ya lista para servir a la guerra como ideología" (1999, p. 137).

\section{Notas}

1. Como cabe esperar, se intenta aquí simplemente una delimitación esquemática con miras al recorte de nuestro objeto.

2. Nótese como caso emblemático la contribución de Moses Mendelssohn al debate sobre el significado de la ilustración en la Berlinische Monatsschrift durante 1784; allí escribe Mendelssohn que "formación, cultura e ilustración son modificaciones de la vida social, efectos de la labor y las preocupaciones de los hombres para mejorar su estado social" (1981, p. 115). Martín Koval (2018) analiza detalladamente esta apropiación por parte de la ilustración alemana en torno a la novela de formación

3. Se lee en Theory, Culture \& Society, una revista que detenta un rol destacado en la recepción de Simmel, que al haber "aplicado el problema del destino a la sociedad", el filósofo habría "contribuido a la conciencia de una responsabilidad social conjunta" (BUTTON, 2012, p. 58s.). Y en un call for papers de la revista Science and Peace se invita a colaborar en un número monográfico dedicado al centenario del ensayo "El conflicto en la cultura moderna" bajo el presupuesto de que el "método simmeliano llama implícitamente a una racionalidad no violenta, dedicado a alcanzar un "nivel modesto de conflicto' o tolerancia, con el fin de preservar un grado relativamente 'suficiente' de paz o integración social" (https:// 
scienzaepace.unipi.it/index.php/en/submit/call-for-papers/georg-simmel. html 12 de junio). Como hemos explicado en otros contextos (GARCIA CHICOTE, 2018), la categoría de carácter lleva en Simmel el nombre de "personalidad" y es central para su concepción de cultura trágica. Si bien tal categoría posee un rol decisivo en toda la ensayística de Simmel, no solo son casi inexistentes los ejercicios críticos en torno a ella, sino que también se constata una desaparación del término en las traducciones al inglés y al español, lo que indica que, así como "cultura", "personalidad" es entendida en términos fácticos y no axiológicos.

4. Para el caso alemán, cf. Hempfer (1973, p. 221), Zymner (2003, p. 57s.).

5. Las diferentes artes provienen de la concentración de las facultades de un sentido para expresar un complejo vital múltiple, de ahí que Lukács conciba la forma como limitación intensificadora: "La forma nace a partir de esta renuncia. El estrechamiento del espacio, la limitación de los medios de expresión en pos de la intensidad de la expresión: esta es la forma" (GLW 1, $1,64)$.

6. Señálese que la teoría del conocimiento que sustenta a la "sociología de la literatura" depende de una fundamentación ontológica para la cual el pensamiento cotidiano, la ciencia y el arte presentan refiguraciones necesariamente distintas de la misma realidad objetiva, lo que supone -para el Lukács de La peculiaridad de lo estético- que "el reflejo de la misma realidad objetiva acarrea la necesidad de trabajar en todos los campos con las mismas categorías" (1982, 1, p. 57). En la Ontología del ser social, Lukács confirma este punto de vista al afirmar que "historia, economía, sociología, politología, demografía etc. conforman ontológicamente un complejo inseparablemente unitario (lo que naturalmente no solo permite investigaciones especializadas, sino también las propicia) $[. .$.$] solamente$ en una constatación práctica metodológicamente fundada de la unidad ontológica del complejo concreto mismo" (2013, p. 284; el resaltado es nuestro).

7. En este ensayo sobre Sterne se expresaría, en palabras Rainer Rochlitz "un universo de malentendidos, de la relatividad universal, de la cotidianidad excéntrica y la emancipación por parte del lenguaje de su dignísima función comunicativa" que anticiparía en cierta medida la lectura que luego Lukács hiciere de James Joyce. Nótese que para Rochlitz, este diálogo expresaría 
la supuesta misoginia del autor. Sin menospreciar en lo más mínimo el carácter sexista, irracional e irracionalista de la configuración de la estudiante en el diálogo, aquí se desatenderá -por motivos desarrollados a continuación- la posible injerencia de factores psicológicos o biográficos en la configuración de las obras (algo, por cierto, que Rochlitz solo tiene en cuenta al pasar, cf. 1983, p. 98s.).

8. Véanse los empeños de Simmel por conformar, a principios de 1903, un "club de personalidades" para el movimiento de secesión modernista (cf. GSG, 22, P. 447ss.).

9. En Kulturwissenschaft und Naturwissenschaft (Ciencia de la cultura y ciencia de la naturaleza), de 1899, se considera el valor como rasgo distintivo de la cultura: "Mediante la referencia a valores, que o bien existe o bien no, podemos entonces separar con seguridad dos objetos de las ciencias. [...] La naturaleza sería luego el ser que se halla libre de significación, que es inentendible, únicamente perceptible, la cultura por el contrario el ser lleno de significación, entendible, y así lo es de hecho" (RICKERT, 1926, pp. 18 y 20).

10. De 1899 es el ensayo del historiador del arte austrohúngaro Alois Riegl "Die Stimmung als Inhalder mordenen Kunst" (El estado de ánimo como contenido del arte moderno).

CRÍTICA DA CUlTuRA E DA ALMA TRÁGICA NA ENSAÍstiCA DE JUVENTUDE DE GYÖRGY LUKÁCS

\section{RESUMO}

Este trabalho aborda um elemento central na conformação do campo intelectual alemão durante o período guilhermino: o conceito de cultura, cuja formulação mais complexa de encontra na obra de Georg Simmel. Se afirma que as conceituações de juventude de György Lukács acerca da tragédia constituem uma crítica destrutiva do conceito de cultura e marcam um antecedente significativo no desenvolvimento do marxismo ocidental.

Palavras-chave: Valor, Rédito, Simmel, Marx. 
ABSTRACT

This article deals with a crucial element in Germany's intellectual field during the Wilhelmine Period: the concept of culture, whose sharpest formulation is to be found in Georg Simmel's oeuvre. The article argues that Gyorgy Lukács' early theorisations on the problem of tragedy are intended towards a critique of the Simmelian theory of culture. Such critique lays the foundation for the ulterior development of Western Marxism.

Keywords: Value, Revenue, Simmel, Marx.

\section{REFERENCIAS}

ADORNO, Theodor W. Dialéctica negativa. Madrid: Editora Nacional, 2002.

BAECKER, Dirk. Kultur. In: BARCK, Karlheinz (Ed.). Ästhetische Grundbegriffe. Historisches Wörterbuch in sieben Bänden: Volumen 3 (Harmonie-Material). Stuttgart: Metzler, 2002. p. 510-556.

BRECHT, Bertolt. Große kommentierte Berliner und Frankfurter Ausgabe. Berlin und Weimar: Aufbau; Frankfurt a/M: Suhrkamp, 1995.

BUTTON, Robert William. Fate, Experience and Tragedy in Simmel's Dialogue with Modernity. Theory, Culture \& Society, n. 29 (7/8), 2012 p. 53-77.

ELIAS, Norbert. El proceso de la civilización. México: FCE, 2009.

FRISBY, David. Georg Simmel: First Sociologist of Modernity. Theory Culture \& Society v. 2, n.3, 1985. p. 49-67.

GIL VILLEGAS, Francisco. El fundamento filosófico de la teoría de la modernidad en Simmel. Estudios sociológicos. v. 15, n. 43, jan.- abr. 1997. p. 3-46.

GARCÍA, George I. Modernidad y cosificación: Simmel y Schütz. Revista de Filosofia de la Universidad de Costa Rica, XLVI (119), 2008. p. 57-68.

GARCIA CHICOTE, Francisco Manuel. El sujeto de la emancipación. Personalidad y capitalismo en György Lukács y Siegfried Kracauer. Los Polvorines: Ediciones UNGS, 2018.

GLW - LUKÁCS, György. Werke. Neuwied \& Berlin: Luchterthand; Bielefeld: Aisthesis Verlag, 1965-2018. 
GOLDMANN, Lucien. Lukács, el ensayista (en su época premarxista). In: STEINER, Georg et al., Lukács. Buenos Aires: Jorge Álvarez, 1969. p. 49-62. GOLDMANN, Lucien. El hombre y lo absoluto. El dios oculto. Buenos Aires: Planeta Agostini, 1986.

GSG - SIMMEL, Georg. Gesamtausgabe. Frankfurt a/M: Suhrkamp, 19892016.

HEMPFER, Klaus W. Gattugnstheorie. München: Fink, 1973.

ISHAGHPOUR, Youssef. Prólogo. In: GOLDMANN, Lucien, Lukács y Heidegger. Hacia una filosofia nueva. Buenos Aires: Amorrortu, 1975. p. 7-46.

KOVAL, Ignacio. Vocación y renuncia. Buenos Aires: Filo-UBA, 2018.

LECK, Ralph. Simmel's Afterlife: Tropic Politics and the Culture of War. New German Critique 75 (Autumn, 1998), 1998. p. 109-132.

LEDERER, Emil. Zur Soziologie des Weltkrieges. In:_, Kapitalismus, Klassenstruktur und Probleme der Demokratie in Deutschland 1910-1940. Göttingen, 1999. p. 119-144.

LUKÁCS, György. “Ariadne auf Naxos”. In: KUTZBACH, Karl August (Ed.), Paul Ernst und Georg Lukács. Dokumente einer Freundschaft. Düsseldorf: Paul-Ernst-Gesellschaft, 1974.

LUKÁCS, György. Acerca de la pobreza de espíritu y otros escritos de juventud. Buenos Aires: Gorla, 2015b.

LUKÁCS, György. Derrotismo y dialéctica. Buenos Aires: Herramienta, 2015a.

LUKÁCS, György. El alma y las formas. Teoría de la novela. Barcelona: Grijalbo, 1985.

LUKÁCS, György. Estética 1. La peculiaridad de lo estético. Barcelona: Grijalbo, 1982.

LUKÁCS, György. Historia y conciencia de clase. México: Grijalbo, 1969.

LUKÁCS, György. Ontología del ser social. La alienación. Buenos Aires: Herramienta, 2013.

MARCUSE, Herbert. Acerca del carácter afirmativo de la cultura. In:

Cultura y sociedad. Trad. de E. Bulygin y E. Garzón Valdés. Buenos Aires: Sur, 1970. p. 45-78.

MARKUS, György. The Soul and Life: The Young Lukács and the Problem of Culture. Telos 32 (June 1977), 1977. p. 95-115. 
MARX, Karl. Contribución a la crítica de la economía política. Buenos Aires: Siglo XXI, 1980.

MARX, Karl. El capital. México: Siglo XXI, 1985.

MARX, Karl. Miseria de la filosofía. Buenos Aires: Cartago, 1987.

MENDELSSOHN, Moses. Was ist Aufklärung? In: _ , Gesammelte Schriften. Tomo 6. 1. (Kleinere Schriften). Stuttgart: Friedrich Fromann, 1981. p. 115-118.

MILLS, Charles W. Las causas de la tercera guerra mundial. Buenos Aires: Mayo, 1969.

RICKERT, Heinrich. Kulturwissenchaft und Naturwissenchaft, Tübingen: J.C.B. Mohr, 1926.

ROCHLITZ, Rainer. Le jeune Lukács. París: Payot, 1983.

SIMMEL, Georg. De la esencia de la cultura. Buenos Aires: Prometeo, 2005a.

SIMMEL, Georg. Filosofía del dinero. Madrid: Capitán Swing, 2013.

SIMMEL, Georg. El individuo y la libertad. Ensayos de crítica de la cultura. Barcelona: Península, 1986.

SIMMEL, Georg. Goethe. Buenos Aires: Prometeo, 2005b.

VEDDA, Miguel. Estudio Preliminar. Entre la metafísica y la historia. Sobre la trayectoria intelectual del joven Lukács. In: LUKÁCS, György. Acerca de la pobreza de espiritu y otros escritos de juventud. Buenos Aires: Gorla, 2015. p. 5-87.

WEBER, Max. El cientifico y el político. Madrid: Alianza, 1979.

ZYMNER, Rüdiger. Gattungstheorie. Probleme und Positionen der Literaturwissenschaft. Paderborn: Mentis, 2003.

Submetido em 27 de agosto de 2018

Aceito em 23 de outubro de 2018

Publicado em 11 de abril de 2019 